\title{
Effect of epidermal growth factor and prostaglandin on the expression of aromatase (CYP19) in human adrenocortical carcinoma cell line $\mathrm{NCI}-\mathrm{H} 295 \mathrm{R}$ cells
}

\author{
Masatada Watanabe, Mariko Noda and Shizuo Nakajin \\ Department of Biochemistry, Hoshi University School of Pharmacy and Pharmaceutical Sciences, 2-4-41 Ebara, Shinagawa, Tokyo 142-8501, Japan \\ (Requests for offprints should be addressed to M Watanabe; Email: masatada@hoshi.ac.jp)
}

\begin{abstract}
We investigated the effects of epidermal growth factor (EGF) and prostaglandins (PG) on the expression of aromatase (CYP19) in human adrenocortical carcinoma cell line NCI-H295R cells. EGF significantly increased aromatase activity and CYP19 gene transcript in NCIH295R cells. Exon PII was selected from among several tissue-specific exon I regions. Promoter II that abuts on exon PII was activated by EGF. PGE 2 also significantly increased aromatase activity, CYP19 gene transcript, and promoter II activity. The results of experiments using protein kinase $(\mathrm{PK})$ inhibitors suggest that the cAMPPKA signaling pathway is involved in the up-regulation of
\end{abstract}

aromatase expression by EGF. $\mathrm{PGE}_{2}$ activated promoter II activity in $4 \mathrm{~h}$, while $12 \mathrm{~h}$ was required for its activation by EGF. In addition, $\mathrm{PGE}_{2}$ was secreted from NCI-H295R cells in response to EGF. Selective agonists for prostaglandin receptors $\mathrm{EP}_{1}$ and $\mathrm{EP}_{2}$ significantly increased aromatase activity, which was decreased by the corresponding antagonists. Finally, antagonists for $\mathrm{EP}_{1}$ and $\mathrm{EP}_{2}$ inhibited the up-regulation of aromatase expression following EGF. These results suggest that $\mathrm{PGE}_{2}$ secondarily acts as an autocrine signal in the up-regulation of aromatase expression by EGF in NCI-H295R cells.

Journal of Endocrinology (2006) 188, 59-68

\section{Introduction}

There have been reports indicating that tumors which secrete abnormally high levels of estrogen cause gynecomastia in boys and men and precocious puberty in girls. In these cases, cytochrome P450 aromatase (CYP19), the key enzyme of estrogen biosynthesis, is highly expressed (Young et al. 1996, Watanabe et al. 2000, Phornphutkul et al. 2001). In another case, a mutation in the promoter region of the CYP19 gene that codes for aromatase caused excess expression of aromatase and progression of gynecomastia (Shozu et al. 2003).

CYP19 gene is composed of multiple untranslated exon $\mathrm{I}$ and coding regions (exon II to exon X) (Bulun et al. 2004). A special feature of the CYP19 gene is its multiple exon I. At least ten exon I regions are selected in a tissue-specific fashion. After alternative splicing, mRNA with a tissue-specific $5^{\prime}$-untranslated region is formed. In this tissue-specific selection of exon I, promoter regions that abut on the $5^{\prime}$-end of each exon I are activated by a distinct signal pathway. For example, promoter II and promoter I. 3 that abut on the $5^{\prime}$-end of exon PII and exon I. 3 respectively, are activated by the signaling pathway that includes the elevation of intracellular cAMP concentration. On the other hand, promoter I.4 that abuts on the $5^{\prime}$-end of exon I.4 is activated by glucocorticoid.
We found previously that forskolin largely up-regulates aromatase expression in NCI-H295R cells, a human adrenocortical carcinoma cell line (Watanabe \& Nakajin 2004). Promoter I.3 and promoter II are activated in NCI-H295R cells. From these findings, we were interested in identifying physiological factors that induce aromatase expression in NCI-H295R cells in order to clarify the mechanism of aromatase expression in adrenal tumors.

Epidermal growth factor (EGF) increases aromatase activity and expression in MCF-7 and adipose stromal cells and induces expression of cyclooxygenase 2 (COX-2) in adipose stromal cells (Richards et al. 2002). In breast tumors, prostaglandin $(\mathrm{PG}) \mathrm{E}_{2}$ increases intracellular cAMP levels and stimulates estrogen biosynthesis (Zhao et al. 1996); furthermore, it up-regulates aromatase activity and expression in adipose stromal cells (Richards \& Brueggemeier 2003). EGF affects the expression of $3 \beta$ -

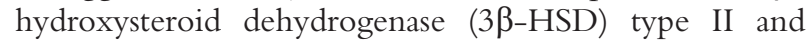
CYP17 in NCI-H295R cells (Doi et al. 2001). Also in NCI-H295R cells, up-regulation of aromatase expression by $\mathrm{PGE}_{2}$ has been reported (Heneweer et al. 2004). However, the mechanisms of the effects of EGF and $\mathrm{PGE}_{2}$ on aromatase expression in NCI-H295R cells have not been examined in detail at the molecular biological level. Therefore, we conducted detailed studies on the effects 
of EGF and prostaglandins on aromatase expression in NCI-H295R cells.

\section{Materials and Methods}

\section{Materials}

EGF was purchased from Cosmo Bio Co. Ltd (Tokyo, Japan). EGF was dissolved in $10 \mathrm{mM}$ acetic acid containing $0 \cdot 1 \%$ BSA. Prostaglandin $\mathrm{A}_{1}\left(\mathrm{PGA}_{1}\right)$ and $\mathrm{PGF}_{2 \alpha}$ were obtained from Cayman Chemical (Ann Arbor, MI, USA). $\mathrm{PGE}_{1}$ and $\mathrm{PGE}_{2}$ were purchased from Sigma Aldrich Japan (Tokyo, Japan). Prostaglandins were dissolved in ethanol. H-89 was purchased from Seikagaku Corporation (Tokyo, Japan) and PD98059 and KN-93 from Cosmo Bio Co. Ltd. Protein kinase inhibitors were dissolved in dimethyl sulfoxide (DMSO). Butaprost, sulprostone, AH6809 and SC-19220 were obtained from Cayman Chemical. ONO-DI-004 and ONO-AE1259-01 (Suzawa et al. 2000, Narumiya \& FitzGerald 2001) were generous gifts provided by Ono Pharmaceutical Co. Ltd (Osaka, Japan). Butaprost, ONO-DI-004 and ONOAE1-259-01 were dissolved in ethanol. Sulprostone, AH6809 and SC-19220 were dissolved in DMSO. The concentration of each solvent was $0 \cdot 1 \%(\mathrm{v} / \mathrm{v})$. D-MEM/ F-12, D-MEM/F-12 without phenol red and a mixture of penicillin $(5000 \mathrm{U} / \mathrm{ml})$ and streptomycin $(5000 \mu \mathrm{g} / \mathrm{ml})$ were purchased from Invitrogen Japan K.K. (Tokyo, Japan). ITS plus was purchased from Nippon Becton Dickinson Company, Ltd (Tokyo, Japan). Nu-Serum I was purchased from Cosmo Bio Co. Ltd and fetal calf serum (FCS) was from Sanko Junyaku (Tokyo, Japan).

Cells

NCI-H295R human adrenocortical carcinoma cells were purchased from the American Type Culture Collection (Manassas, VA, USA). NCI-H295R cells were cultured in D-MEM/F-12 supplemented with $50 \mathrm{U} / \mathrm{ml}$ penicillin, $50 \mu \mathrm{g} / \mathrm{ml}$ streptomycin, $1 \%(\mathrm{v} / \mathrm{v})$ ITS plus and $2 \cdot 5 \%(\mathrm{v} / \mathrm{v})$ $\mathrm{Nu}$-Serum I. The human granulosa-like cell line KGN (Nishi et al. 2001) was obtained from Riken Cell Bank (Tsukuba, Japan). KGN cells were cultured in D-MEM/ F-12 medium supplemented with penicillin $(50 \mathrm{U} / \mathrm{ml})$, streptomycin $(50 \mu \mathrm{g} / \mathrm{ml})$ and FCS $(10 \% \mathrm{v} / \mathrm{v})$. Cells were maintained as monolayer cultures in $10-\mathrm{cm}$ dishes at $37^{\circ} \mathrm{C}$ in an atmosphere of $5 \% \mathrm{CO}_{2}-95 \%$ air.

\section{Aromatase assay}

NCI-H295R cells were seeded at a density of $5.0 \times 10^{5}$ cells/well on $24-w e l l$ plates. After 48 -h culture, the medium was replaced with the treatment medium (D-MEM/F-12 without phenol red with $1 \%(\mathrm{v} / \mathrm{v})$ ITS plus, penicillin $(50 \mathrm{U} / \mathrm{ml})$ and streptomycin $(50 \mathrm{mg} / \mathrm{ml}))$.
After incubation for $24 \mathrm{~h}$ (serum starvation), the cells were treated with treatment medium that contained peptide or chemical compounds. After incubation, aromatase activity in the NCI-H295R cells was measured by the tritiated water method described previously (Watanabe \& Nakajin 2004).

\section{$R T-P C R$}

After serum starvation, the NCI-H295R cells were treated with EGF for $24 \mathrm{~h}$ or $\mathrm{PGE}_{2}$ for $4 \mathrm{~h}$. Then, total RNA was extracted using ISOGEN (Nippongene, Toyama, Japan). First-strand cDNA was prepared from total RNA using Oligo $(\mathrm{dT})_{15}$ primer (Promega, Madison, WI, USA), human placenta ribonuclease inhibitor (Takara Shuzo, Shiga, Japan) and AMV reverse transcriptase (Promega) according to the manufacturers' instructions. The RT-PCR of the gene transcripts of EGF receptor (EGFR), CYP19 (coding region (exon IX-X) and exon PII-including $5^{\prime}$ region), glyceraldehyde-3phosphate dehydrogenase (GAPDH) and prostaglandin receptors $\left(\mathrm{EP}_{1}, \mathrm{EP}_{2}, \mathrm{EP}_{3}\right.$ and $\left.\mathrm{EP}_{4}\right)$ were based on published data (Moroni et al. 2001, Schlotzer-Schrehardt et al. 2002, Iwasaki et al. 2003, Richards \& Brueggemeier 2003, Watanabe \& Nakajin 2004). The PCR products were visualized with ethidium bromide after electrophoresis on $1.5 \%$ agarose gel, and quantified by calculating the intensity of the band of the PCR product of CYP19 (coding region (exon IX-X) and exon PII-including $5^{\prime}$ region) relative to the intensity of the band of the PCR product of GAPDH.

\section{Transfection and luciferase assay}

NCI-H295R cells were seeded at a density of $5 \cdot 0 \times 10^{5}$ cells/well on 24-well plates. After culturing for $24 \mathrm{~h}$, firefly luciferase reporter vectors harboring various lengths of promoter I.3/II or empty firefly luciferase vector (pGL3-Basic) and sea pansy luciferase internal control vector (phRL-TK) were transfected using Fugene 6 transfection reagent (Roche Diagnostics K.K., Tokyo, Japan). After 24-h transfection, the cells were serum starved for $4 \mathrm{~h}$. The cells were then treated with peptides and chemical compounds. After treatment, the cells were lysed and luciferase activities in the lysate were measured using a Dual-Luciferase reporter assay (Promega) and a Sirius luminometer (Berthold Detection Systems, Pforzhein, Germany).

\section{Enzyme immunoassay of $\mathrm{PGE}_{2}$}

The concentration of $\mathrm{PGE}_{2}$ in the conditioned media of NCI-H295R cells that were treated with EGF for 

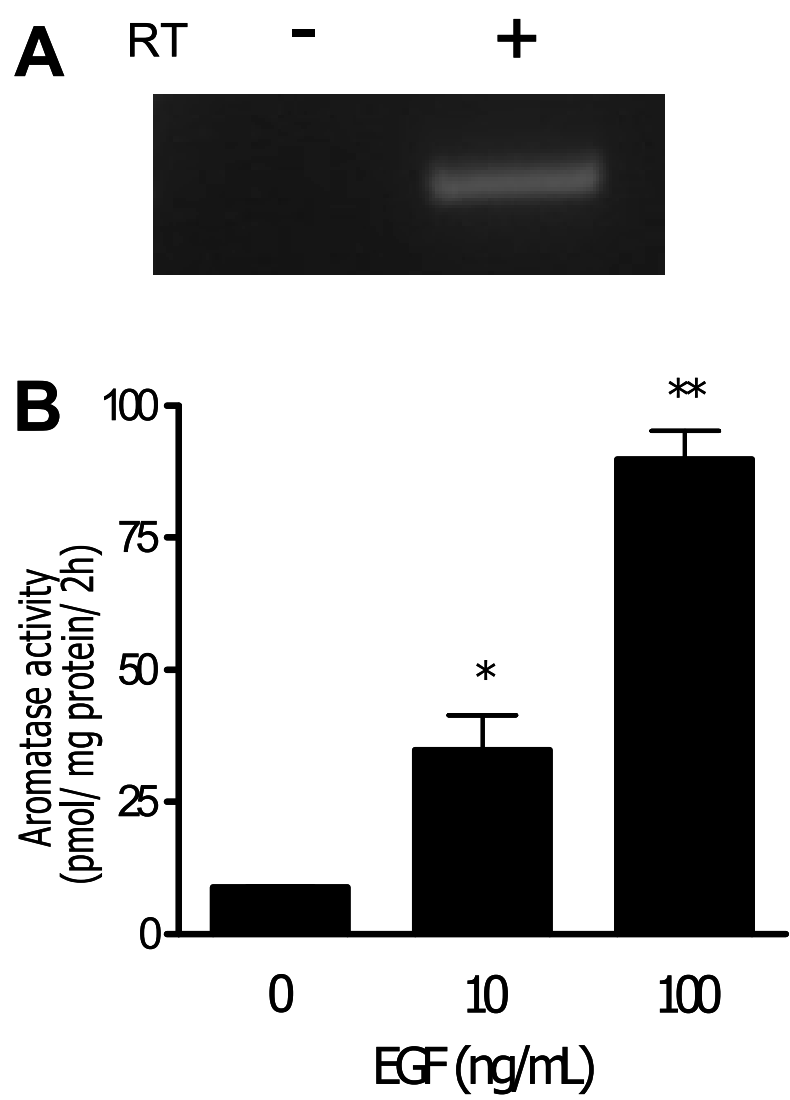

Figure 1 EGF increases aromatase activity in NCl-H295R cells. (A) Result of RT-PCR for EGF receptor gene transcript in $\mathrm{NCl}-\mathrm{H} 295 \mathrm{R}$ cells. RT - and + indicate cDNA preparation without and with the reverse transcriptase. (B) Increase in aromatase activity in $\mathrm{NCl}$ H295R cells by EGF. After serum starvation for $24 \mathrm{~h}$ and then EGF treatment for $24 \mathrm{~h}$, aromatase activity was measured. Each column represents the mean with S.E.M. $(n=3)$. The differences between means were analyzed by one-way ANOVA followed by Tukey's multiple comparison test. Asterisks denote significant differences compared with the vehicle control $(0 \mathrm{ng} / \mathrm{ml}) ;{ }^{*} P<0 \cdot 05 ;{ }^{* *} P<0 \cdot 01$.

$24 \mathrm{~h}$ was measured using Prostaglandin $\mathrm{E}_{2}$ EIA Kit Monoclonal (Cayman Chemical).

\section{Statistical analysis}

The statistical significance of experimental data was determined by one-way ANOVA followed by the Dunnett, Tukey, or Bonferroni/Dunn tests for multiple comparisons.

\section{Results}

Effect of EGF on aromatase expression in NCI-H295R cells

Before evaluation of the effect of EGF, we tested the expression of EGF receptor (EGFR) gene transcript in NCI-H295R cells by RT-PCR. As shown in Fig. 1A, the EGFR gene transcript was expressed in NCI-H295R cells. We then tested the effect of EGF on aromatase expression in NCI-H295R cells. As shown in Fig. 1B, aromatase activity in the cells was significantly increased by EGF in a concentration-dependent fashion. We also tested the effect of EGF on the expression of the CYP19 gene. As shown in Fig. 2A and B, one of the CYP19 gene transcripts corresponding to the coding region and the other gene transcript which includes exon PII were both up-regulated by EGF in a concentration-dependent manner. These results suggest that EGF up-regulates aromatase expression at the level of CYP19 gene expression in NCI-H295R cells.

Effect of EGF on promoter I.3/II activity of the CYP19 gene

There are two cAMP-responsive promoter regions upstream of exon PII in the CYP19 gene. Promoter II abuts on the $5^{\prime}$-end of exon PII and this promoter includes the sequence of exon I.3. Promoter I.3 abuts on exon I.3. To clarify the mechanism of CYP19 gene expression, we transfected the firefly luciferase reporter constructs that harbor several $5^{\prime}$-deleted promoter I.3/II sequences as shown in Fig. 3. The results in Fig. 4 show that the reporter activity (promoter activity) of $-717 /+23$ Luc was activated significantly and in a concentrationdependent fashion by treatment with EGF for $12 \mathrm{~h}$. This result suggests that activation of the promoter region that abuts on the $5^{\prime}$-end of exon PII is involved in the up-regulation of aromatase expression by EGF.

To clarify the sequence that is important for the activation of promoter I.3/II, we transfected the deletion constructs into NCI-H295R cells, treated the cells with $100 \mathrm{ng} / \mathrm{ml} \mathrm{EGF}$, and then measured promoter activity. As shown in Fig. 5, - 717/+23 Luc and $-278 /+23$ Luc had the same promoter activity. However, the promoter activity of $-227 /+23$ Luc, which has a deletion sequence that includes TATA of promoter I.3, was less than half that of $-278 /+23$ Luc. This result suggests that the 51 base pair sequence that includes TATA of promoter I.3 is important for the promoter activity. In addition, $-198 /+23$ Luc was still activated significantly by EGF, while $-119 /+23$ Luc was not significantly activated. This result suggests that the 79 base pair sequence between -198 and -119 in promoter II is critical for the activation of promoter I.3/II by EGF.

Effects of prostaglandins on aromatase expression in NCI-H295R cells

We tested the effects of prostaglandins (prostaglandin $A_{1}$ $\left(\mathrm{PGA}_{1}\right), \mathrm{PGB}_{2}, \mathrm{PGD}_{2}, \mathrm{PGE}_{1}, \mathrm{PGE}_{2}$ and $\mathrm{PGF}_{2 \alpha}$ ) on aromatase expression in NCI-H295R cells. As shown in Fig. 6, all the prostaglandins except $\mathrm{PGF}_{2 \alpha}$ increased aromatase activity significantly. The increases in aromatase activity by $\mathrm{PGE}_{1}$ and $\mathrm{PGE}_{2}$ were particularly large. 

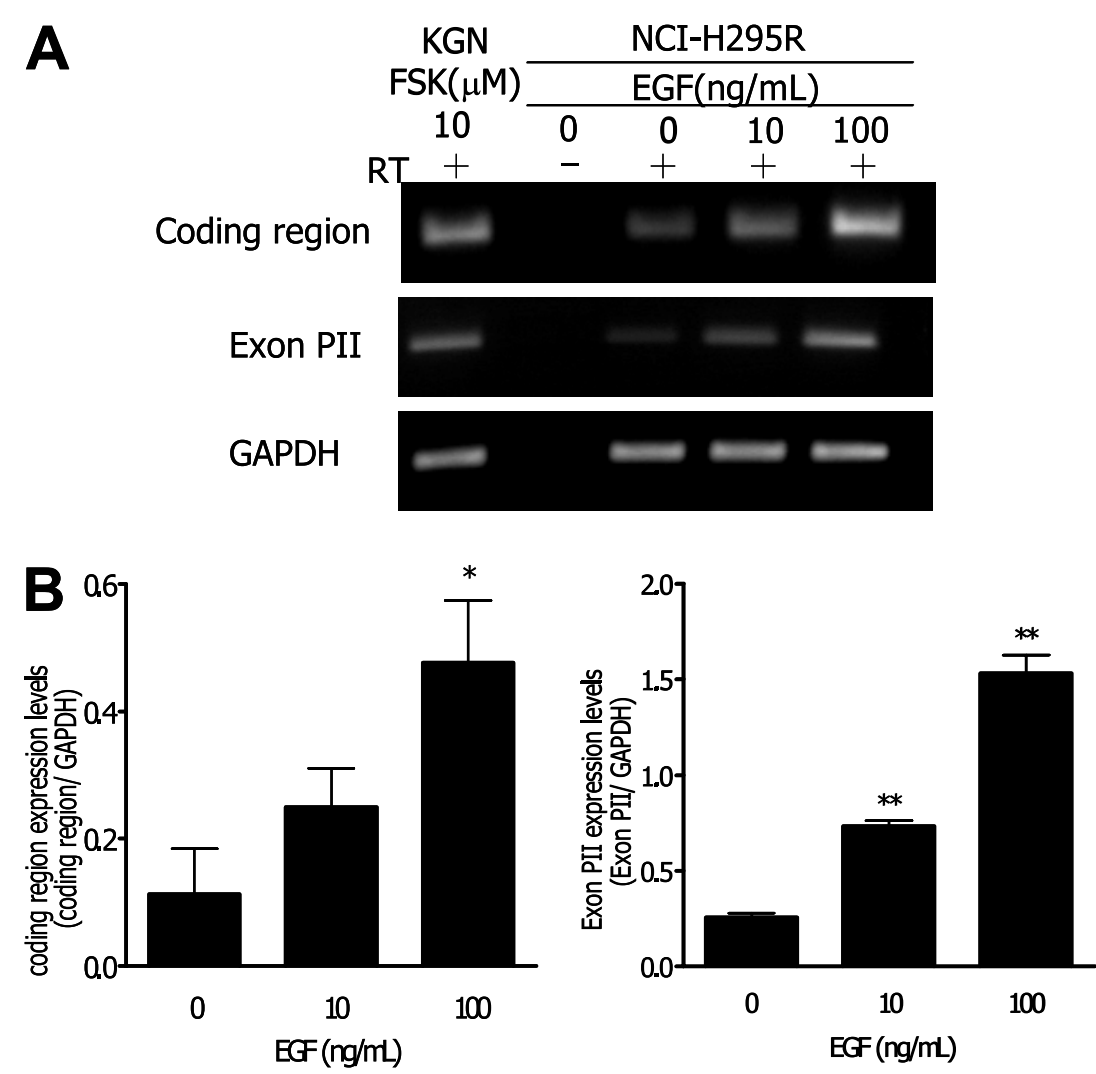

Figure 2 EGF up-regulates CYP19 gene transcripts in NCl-H295R cells. (A) Results of RT-PCR for coding region and exon PII of CYP19 gene transcripts and GAPDH gene transcript. Total RNA was extracted after serum starvation for $24 \mathrm{~h}$ and then EGF treatment for $24 \mathrm{~h}$. Then, cDNAs were prepared. cDNA prepared from total RNA of the human ovary-derived cell line KGN and treated with forskolin (FSK) was used as the positive control. RT - and RT + indicate cDNA preparation without and with the reverse transcriptase. (B) Quantification of expression level of coding region and exon PII of CYP19 gene transcript. The intensities of the bands of RT-PCR corresponding to coding region and exon PII were normalized with the bands of GAPDH. Each column represents the mean with S.E.M. $(n=3)$. The differences between means were analyzed by one-way ANOVA followed by Dunnett's multiple comparison test. Asterisks denote significant differences compared with the vehicle control $(0 \mathrm{ng} / \mathrm{ml}) ;{ }^{*} P<0 \cdot 05 ;{ }^{*} P<0 \cdot 01$.

Based on these findings, we concentrated our efforts on the effect of $\mathrm{PGE}_{2}$. As shown in Fig. 7A, four subtypes of prostaglandin receptors $\left(\mathrm{EP}_{1}, \mathrm{EP}_{2}, \mathrm{EP}_{3}\right.$ and $\left.\mathrm{EP}_{4}\right)$ were expressed in NCI-H295R cells. Furthermore, as shown in Fig. 7B, aromatase activity in NCI-H295R cells was increased by $\mathrm{PGE}_{2}$ significantly and in a concentrationdependent manner. As shown in Fig. 8A and B, CYP19 gene transcripts which include the coding region and exon PII sequences were both up-regulated in response to $\mathrm{PGE}_{2}$ in a concentration-dependent fashion. These results suggest that $\mathrm{PGE}_{2}$ up-regulates aromatase expression at the level of CYP19 gene expression.

\section{Effect of PGE $E_{2}$ on the promoter I.3/II activity of CYP19} gene

As was the case for EGF, we tested the effect of $\mathrm{PGE}_{2}$ on promoter I.3 and promoter II. As shown in Fig. 9, the promoter activity of $-717 /+23$ Luc was activated significantly and in a concentration-dependent fashion. $\mathrm{PGE}_{2}$ activated promoter activity in $4 \mathrm{~h}$ whereas upregulation with EGF required $12 \mathrm{~h}$. We also tested the effect of $\mathrm{PGE}_{2}$ on a deletion construct of promoter I.3/II. As shown in Fig. 10, reporter activity decreased as the promoter length was shortened. The deletion construct - 198/ + 23 Luc was still activated by $\mathrm{PGE}_{2}$ significantly, while $-119 /+23 \mathrm{Luc}$ was not activated significantly. This result suggests that the 79 base pair sequence between -198 and -119 in promoter II includes an important sequence, as was the case for EGF.

\section{Effects of EP receptor-specific agonists and an antagonist}

To elucidate which $\mathrm{PGE}_{2}$ receptor $\left(\mathrm{EP}_{1}, \mathrm{EP}_{2}\right.$ and $\left.\mathrm{EP}_{3}\right)$ is involved in the induction of aromatase expression, 


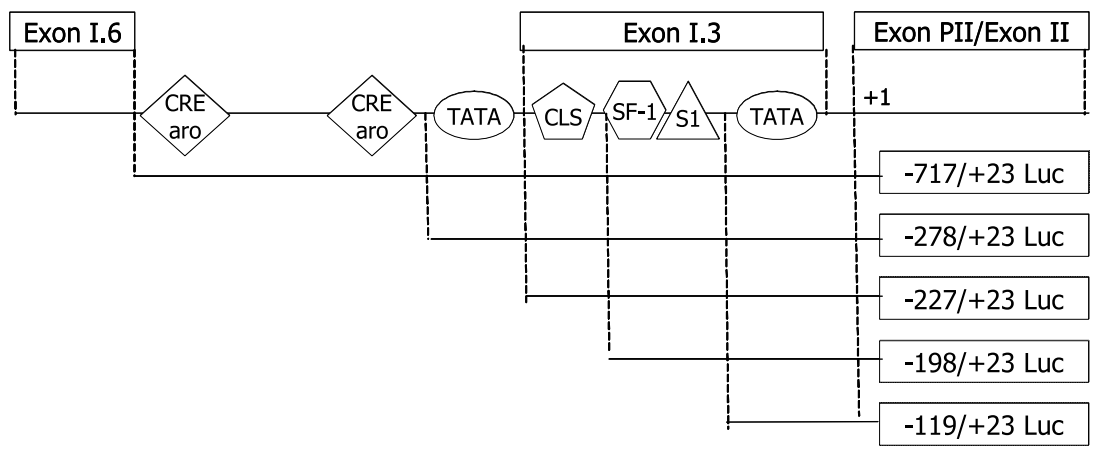

Figure 3 Position of multiple exon I and putative transcription factor binding sites around exon II of the human CYP19 gene. The positions of multiple exon I (top) and transcription factor binding sites (middle: CREaro, TATA, CLS, SF-1, S1) in the partial genomic sequence of the CYP19 gene are indicated. The positions of genomic sequences inserted into firefly luciferase reporter vector (bottom) are also indicated.

we compared aromatase activity in the presence of some agonists and an antagonist. As shown in Fig. 11, aromatase activity was induced by ONO-DI-004 (selective agonist for $\mathrm{EP}_{1}$ ), ONO-AE1-259-01 (selective agonist for $\mathrm{EP}_{2}$ ) and butaprost (selective agonist for $\mathrm{EP}_{2}$ ). These inductions were completely inhibited by AH6809 (antagonist for $\mathrm{EP}_{1}$ and $\mathrm{EP}_{2}$ ). It was not possible to obtain specific agonists and antagonists for $\mathrm{EP}_{4}$. These data suggest that $\mathrm{EP}_{1}$ and $\mathrm{EP}_{2}$ are involved in the induction of aromatase in NCIH295R cells. The fact that there was no induction by sulprostone (selective agonist for $\mathrm{EP}_{3}$ ) suggests that $\mathrm{EP}_{3}$ is not involved in the induction.

\section{Effects of protein kinase inhibitors}

We tested the effects of several protein kinase (PK) inhibitors to elucidate the intracellular signaling pathways

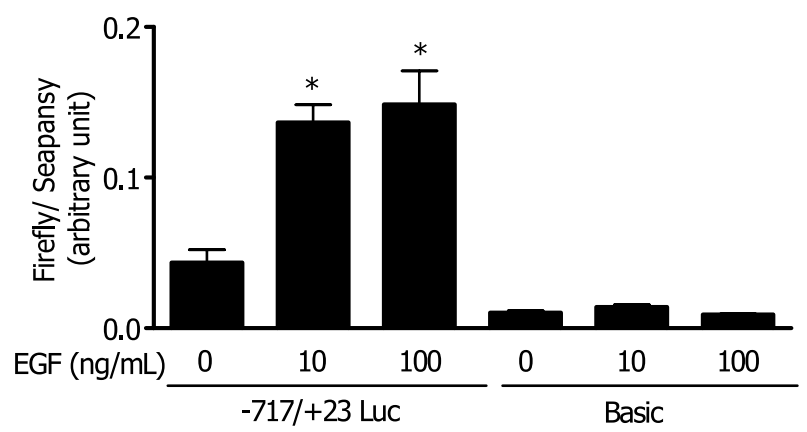

Figure 4 EGF activates promoter I.3/II region in NCI-H295R cells. $-717 /+23$ Luc firefly luciferase reporter vector or empty firefly luciferase vector (Basic) was transfected into NCl-H295R cells with a sea pansy luciferase internal control vector (phRL-TK) using Fugene 6 transfection reagent. After transfection for $24 \mathrm{~h}$ and then serum starvation for $4 \mathrm{~h}$, cells were treated with EGF for $12 \mathrm{~h}$. Then, luciferase activity in the cell lysate was measured. Each column represents the mean with S.E.M. $(n=3)$. The differences between means were analyzed by one-way ANOVA followed by Dunnett's multiple comparison test. Asterisks denote significant differences compared with the vehicle control $(0 \mathrm{ng} / \mathrm{ml})$; ${ }^{\star} P<0 \cdot 05$. that up-regulate aromatase expression. As shown in Fig. 12, up-regulation of aromatase activity by EGF was significantly inhibited to varying degrees by PD98059 (inhibitor of MAP kinase kinase), KN-93 (inhibitor of calcium-calmodulin kinase II) and H-89 (inhibitor of PKA). Aromatase activity was down-regulated to $35 \cdot 3 \%$ of the value with EGF alone by PD98059. Aromatase activity was below the control level in the presence of KN-93. Interestingly, aromatase activity was downregulated to $21 \cdot 1 \%$ by $\mathrm{H}-89$ (Fig. 12A). This result suggests that the cAMP-PKA pathway is involved in the up-regulation of aromatase in response to EGF. The aromatase activity in response to $\mathrm{PGE}_{2}$ was downregulated to $65.9 \%$ of the value with $\mathrm{PGE}_{2}$ alone by

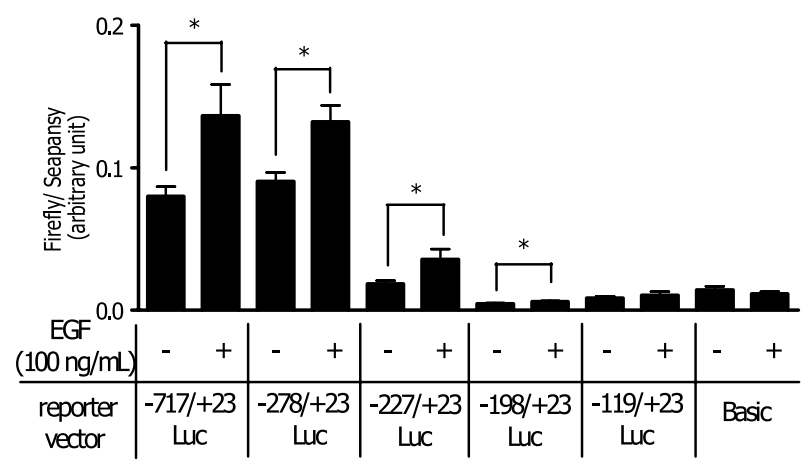

Figure 5 Effect of EGF on the activity of the deletion series of promoter I.3/II sequence. 5 '-deleted series of firefly luciferase reporter vector that were shown in Fig. 3 or empty firefly luciferase vector (Basic) were transfected into $\mathrm{NCl}-\mathrm{H} 295 \mathrm{R}$ cells with a sea pansy luciferase internal control vector (phRL-TK) using Fugene 6 transfection reagent. After transfection for $24 \mathrm{~h}$ and then serum starvation for $4 \mathrm{~h}$, cells were treated with EGF for $12 \mathrm{~h}$. Then, luciferase activity in the cell lysate was measured. Each column represents the mean with S.E.M. $(n=3)$. The differences between means were analyzed by one-way ANOVA followed by Bonferroni/Dunn's multiple comparison test. Asterisks denote significant differences compared with the vehicle control $(-)$; ${ }^{*} P<0 \cdot 05$. 


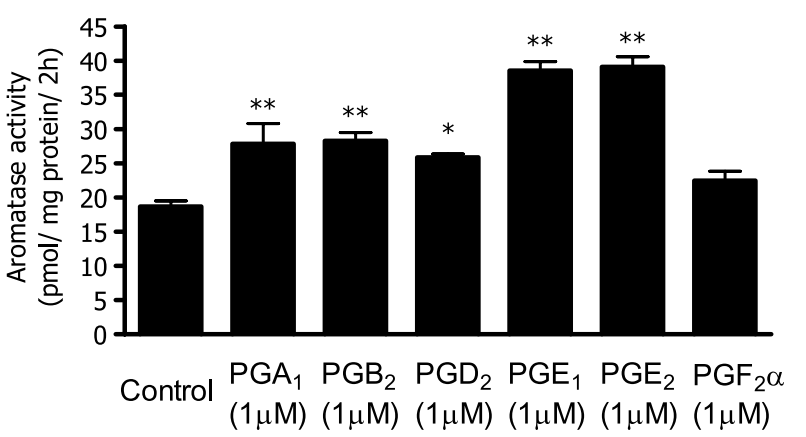

Figure 6 Effect of various prostaglandins (PGs) on aromatase activity in $\mathrm{NCl}-\mathrm{H} 295 \mathrm{R}$ cells. After serum starvation for $24 \mathrm{~h}$, cells were treated with PGs for $4 \mathrm{~h}$. Then, aromatase activity was measured. Each column represents the mean with S.E.M. $(n=3)$. The differences between means were analyzed by one-way ANOVA followed by Dunnett's multiple comparison test. Asterisks denote significant differences compared with the vehicle control; ${ }^{*} P<0 \cdot 05$; ${ }^{*} P<0 \cdot 01$.

PD 98059 and to $42 \cdot 4 \%$ by KN-93. H-89 almost completely diminished aromatase activity (Fig. 12B). These results suggest that the cAMP-PKA pathway is the main signaling pathway in the up-regulation of aromatase in response to $\mathrm{PGE}_{2}$. These results also suggest that the cAMP-PKA pathway evoked in response to $\mathrm{PGE}_{2}$ would be involved in the up-regulation of aromatase expression in response to EGF in NCI-H295R cells.

\section{EGF induces $P G E_{2}$ secretion from NCI-H295R cells}

The results of the experiments using several protein kinase inhibitors suggest that the $\mathrm{PGE}_{2}-\mathrm{CAMP}-\mathrm{PKA}$ pathway may be involved in the up-regulation of aromatase expression in response to EGF. $\mathrm{PGE}_{2}$ secreted from NCIH295R cells in response to EGF may stimulate the cells in an autocrine fashion. Based on this, we attempted to determine whether $\mathrm{PGE}_{2}$ is secreted from NCI-H295R cells in response to EGF. As shown in Fig. 13, the secretion of $\mathrm{PGE}_{2}$ in conditioned media increased in a concentration-dependent manner in response to EGF, but the secretion of $\mathrm{PGD}_{2}$ and $\mathrm{PGE}_{1}$ did not respond to $\mathrm{EGF}$ (data not shown). This result suggests that $\mathrm{PGE}_{2}$ acts partly as a secondary factor in the up-regulation of aromatase expression by EGF.

EP receptor antagonists down-regulate aromatase activity which is induced by EGF

To confirm that $\mathrm{PGE}_{2}$ is the secondary factor in upregulation of aromatase expression by EGF, we tested if EP receptor antagonists inhibit the induction of aromatase expression by EGF. As shown in Fig. 14, induction of aromatase activity with EGF was inhibited with AH6809 (antagonist for $\mathrm{EP}_{1}$ and $\mathrm{EP}_{2}$ ) and $\mathrm{SC}-19220$ (selective antagonist for $\mathrm{EP}_{1}$ ). This result suggests that the $\mathrm{PGE}_{2}$
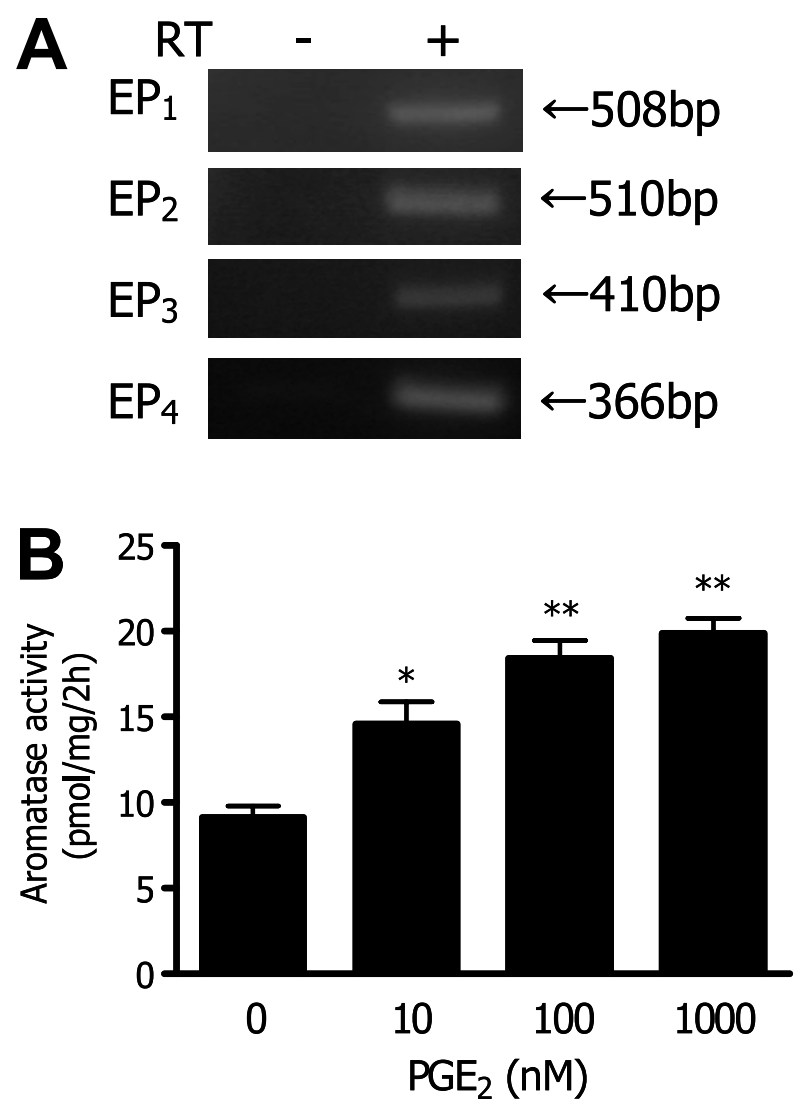

Figure $7 \mathrm{PGE}_{2}$ increased aromatase activity in $\mathrm{NCl}-\mathrm{H} 295 \mathrm{R}$ cells. (A) Results of RT-PCR for gene transcripts of $\mathrm{PGE}_{2}$ receptors in $\mathrm{NCl}-\mathrm{H} 295 \mathrm{R}$ cells. $\mathrm{RT}$ - and + indicate cDNA preparation without and with the reverse transcriptase. Arabic numericals on the right indicate the length of base pairs of RT-PCR product. (B) Increase in aromatase activity in $\mathrm{NCl}-\mathrm{H} 295 \mathrm{R}$ cells by $\mathrm{PGE}_{2}$. Each column represents the mean with S.E.M. $(n=3)$. The differences between means were analyzed by one-way ANOVA followed by Dunnett's multiple comparison test. Asterisks denote significant differences compared with the vehicle control $(0 \mathrm{ng} / \mathrm{ml}) ;{ }^{*} P<0 \cdot 05 ;{ }^{*} P<0 \cdot 01$.

signaling pathway (at least $\mathrm{EP}_{1}$ and $\mathrm{EP}_{2}$ ) is involved in the induction of aromatase expression in NCI-H295R cells by EGF.

\section{Discussion}

Aromatase is not expressed in normal adrenal cortex, but it is expressed after carcinogenesis. This fact suggests that there would be common molecular mechanisms between carcinogenesis and aromatase expression in adrenocortical carcinoma. Therefore, investigation of the mechanism of CYP19 gene expression in estrogen-secreting adrenocortical carcinomas may supply helpful data for determining the mechanism of carcinogenesis in the adrenal cortex. An adrenocortical carcinoma itself or its primary culture would be suitable tools for this kind of investigation. 

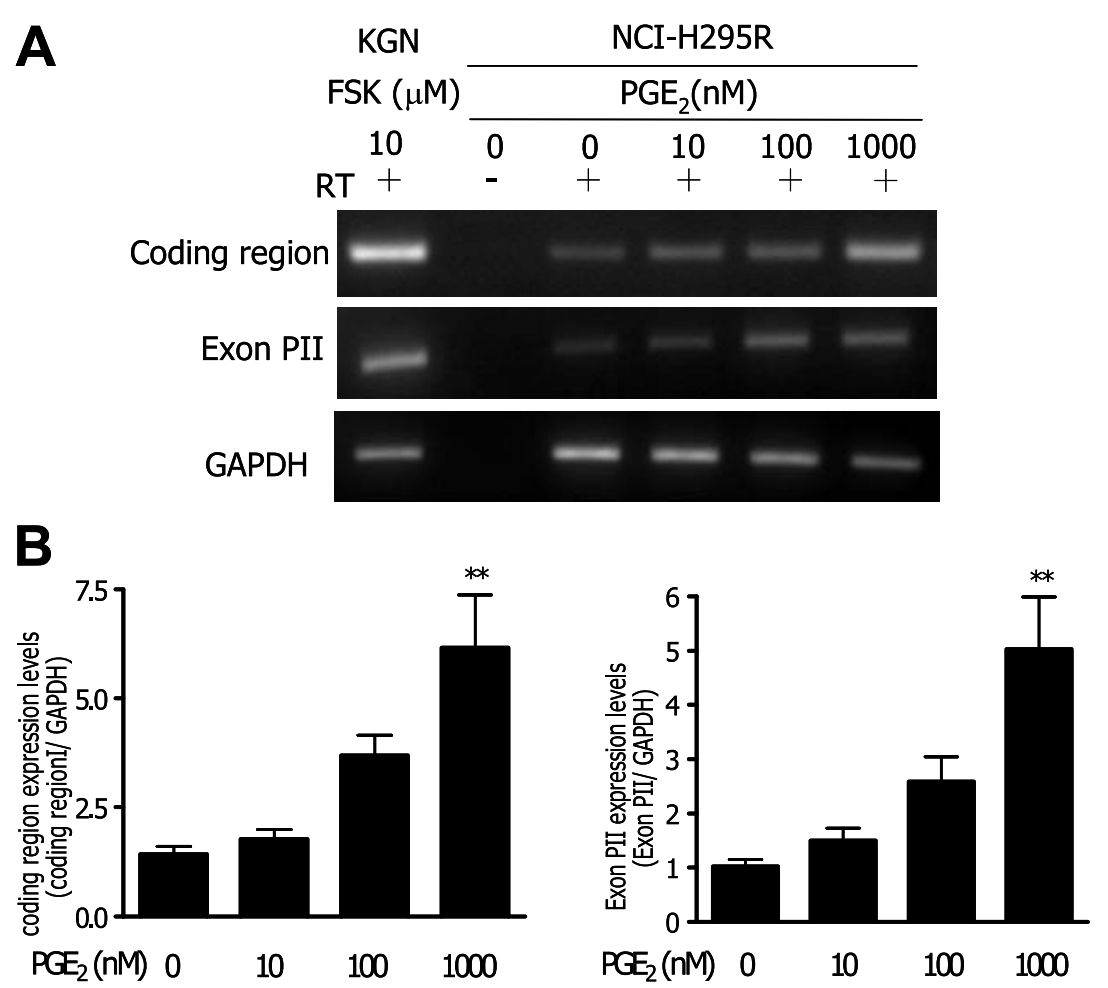

Figure $8 \mathrm{PGE}_{2}$ up-regulates CYP19 gene transcripts in NCl-H295R cells. (A) Results of RT-PCR of coding region and exon PII of CYP19 gene transcripts and GAPDH gene transcript. After serum starvation for $24 \mathrm{~h}$ and $\mathrm{PGE}_{2}$ treatment for $4 \mathrm{~h}$, total RNAs were extracted. Then, cDNAs were prepared. cDNA prepared from total RNA of the human ovary-derived cell line KGN and treated with forskolin (FSK) was used as the positive control. RT - and RT + indicate cDNA preparation without and with the reverse transcriptase. (B) Quantification of expression level of coding region and exon PII of CYP19 gene transcripts. The intensities of the bands of RT-PCR corresponding to coding region and exon PII were normalized with the bands of GAPDH. Each column represents the mean with S.E.M. $(n=3)$. The differences between means were analyzed by one-way ANOVA followed by Dunnett's multiple comparison test. Asterisks denote significant differences compared with the vehicle control $(0 \mathrm{ng} / \mathrm{ml})$; ${ }^{* *} P<0 \cdot 01$.

However, because of the shortage of estrogen-secreting adrenocortical carcinomas and the difficulty associated with molecular investigation (e.g. transfection experiments), these tools are not suitable for studying the molecular biological mechanism. On the other hand, a cell line that is established from an adrenal tumor is easy to culture and stock, and the cell line is easily transfected. Taking into consideration these features, the human adrenocortical carcinoma cell line NCI-H295R can be a useful model of estrogen-secreting adrenocortical carcinoma.

The effects of EGF and $\mathrm{PGE}_{2}$ on aromatase activity and expression have been well studied in human adipose stromal cells (Richards et al. 2002, Richards \& Brueggemeier 2003). The up-regulation of aromatase activity and gene transcript with $\mathrm{PGE}_{2}$ in $\mathrm{H} 295 \mathrm{R}$ cells has been reported (Heneweer et al. 2004).

In this study, we investigated the molecular biological mechanism of the up-regulation of aromatase expression in NCI-H295R cells in response to EGF and $\mathrm{PGE}_{2}$. Both EGF and $\mathrm{PGE}_{2}$ up-regulated aromatase expression at the level of CYP19 gene transcription. The results of transfection experiments using a deletion construct of promoter I.3/II suggest the existence of an important sequence in the 79 base pairs between -198 and -119 in promoter II. The binding site for steroidogenic factor 1 (SF-1) is in this sequence. Since the mutation in SF-1 site abolished the response of promoter II to forskolin (Watanabe \& Nakajin 2004), SF-1 or another transcription factor that binds to this site must have an important role.

EGF, a ubiquitous hormone, would exert its effect on the adrenal cortex in an endocrine fashion. Furthermore, transforming growth factor- $\alpha$, which has a similar structure to EGF and is able to bind to EGFR, is expressed in adrenal cortex (Sasano et al. 1994). Based on these observations, downstream of the EGFR signaling pathway could be evoked in adrenocortical carcinomas. 


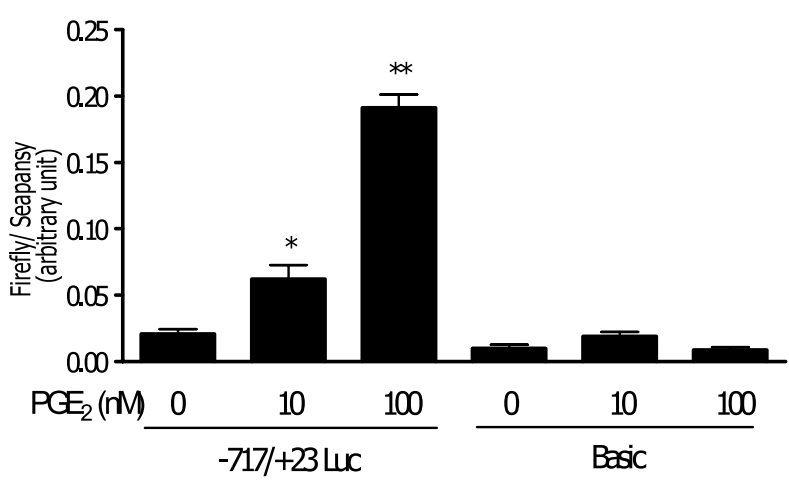

Figure $9 \mathrm{PGE}_{2}$ activates promoter I.3/II region in $\mathrm{NCl}-\mathrm{H} 295 \mathrm{R}$ cells. $-717 /+23$ Luc firefly luciferase reporter vector or empty firefly luciferase vector (Basic) was transfected into $\mathrm{NCl}-\mathrm{H} 295 \mathrm{R}$ cells with a sea pansy luciferase internal control vector (phRL-TK) using Fugene 6 transfection reagent. After transfection for $24 \mathrm{~h}$ and then serum starvation for $4 \mathrm{~h}$, cells were treated with $\mathrm{PGE}_{2}$ for $4 \mathrm{~h}$. Luciferase activity in the cell lysate was then measured. Each column represents the mean with S.E.M. $(n=3)$. The differences between means were analyzed by one-way ANOVA followed by Dunnett's multiple comparison test. Asterisks denote significant differences compared with the vehicle control $(0 \mathrm{ng} / \mathrm{ml}) ;{ }^{*} P<0 \cdot 05$; ${ }^{*} * P<0 \cdot 01$.

Prostaglandins can be synthesized in an adrenocortical carcinoma, and they can work in an autocrine or paracrine fashion. In rabbit chondrocyte and human squamous carcinoma cell lines, EGF induced the secretion of $\mathrm{PGE}_{2}$ via up-regulation of the activities of phospholipase $A_{2}$ $\left(\mathrm{PLA}_{2}\right)$ and COX-2 (Sato et al. 1997, Huh et al. 2003). This may suggest that $\mathrm{PGE}_{2}$ acts as a secondary factor

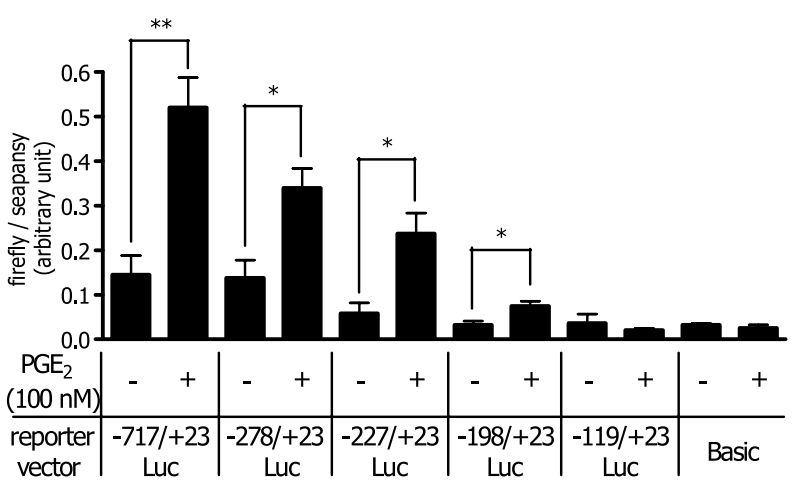

Figure 10 Effect of $\mathrm{PGE}_{2}$ on the activity of the deletion series of promoter I.3/II sequence. 5'-deleted series of firefly luciferase reporter vector that were shown in Fig. 3 or empty firefly luciferase vector (Basic) were transfected into NCl-H295R cells with a sea pansy luciferase internal control vector (phRL-TK) using Fugene 6 transfection reagent. After transfection for $24 \mathrm{~h}$ and then serum starvation for $4 \mathrm{~h}$, cells were treated with $\mathrm{PGE}_{2}$ for $4 \mathrm{~h}$. Then, luciferase activity in the cell lysate was measured. Each column represents the mean with S.E.M. $(n=3)$. The differences between means were analyzed by one-way ANOVA followed by Bonferroni/Dunn's multiple comparison test. Asterisks denote significant differences compared with the vehicle control $(-)$; ${ }^{*} P<0 \cdot 05 ;{ }^{*} P<0 \cdot 01$.

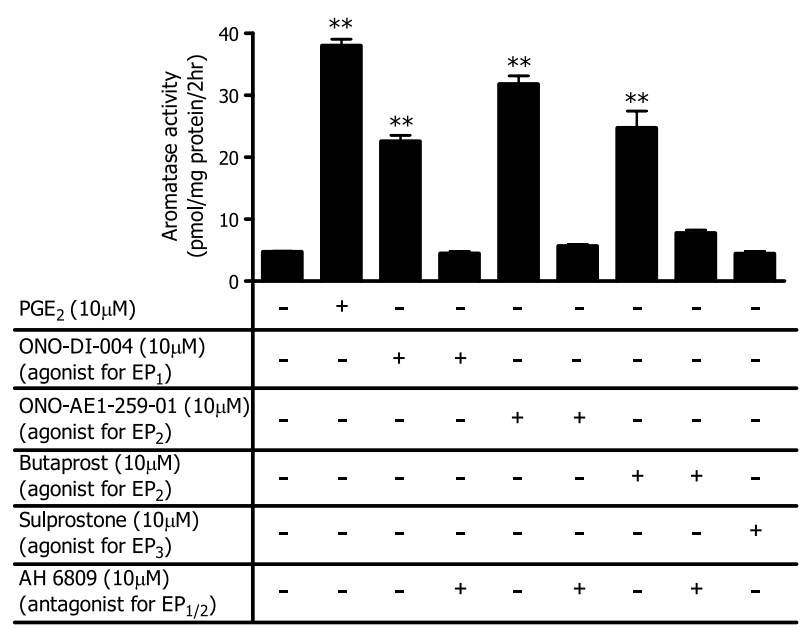

Figure 11 Effects of several EP agonists and an antagonist on aromatase expression. After serum starvation for $24 \mathrm{~h}$, the cells were treated with $\mathrm{PGE}_{2}$ or several agonists and/or an antagonist for EP receptors as shown for $24 \mathrm{~h}$ and then the aromatase activities were measured. Each column represents the mean with S.E.M. $(n=3)$. The differences between means were analyzed by one-way ANOVA followed by Dunnett's multiple comparison test. Asterisks denote significant differences compared with the vehicle control (first column); ${ }^{* *} P<0 \cdot 01$.

to EGF in the up-regulation of aromatase expression. Therefore, we checked whether $\mathrm{PGE}_{2}$ was secreted from NCI-H295R cells in response to EGF. In this study, NCI-H295R cells secreted $\mathrm{PGE}_{2}$ in response to EGF (Fig. 13), and $\mathrm{PGE}_{2}$ increased aromatase activity to a greater extent than other prostaglandins (Fig. 6). The inhibition of EGF-induced aromatase expression with $\mathrm{PGE}_{2}$ receptor antagonists confirmed that $\mathrm{PGE}_{2}$ is the secondary factor of aromatase expression with EGF (Fig. 14). $\mathrm{PGE}_{1}$ also increased aromatase activity to a degree similar to that of $\mathrm{PGE}_{2}$, but EGF could not stimulate NCI-H295R cells to secrete a sufficient concentration of $\mathrm{PGE}_{1}$ (data not shown) to increase aromatase activity. These results suggest that several prostaglandins are secreted in response to EGF, and that these prostaglandins evoke some intracellular signaling pathways. According to the experiments using several protein kinase inhibitors (Fig. 12), the intracellular signaling pathways that include MAP kinase, and calcium-calmodulin kinase are important for up-regulation of aromatase by EGF. In response to EGF, EGF receptors (receptor-type tyrosine kinase) activate the MAP kinase pathway through phosphorylation of Ras protein. It is also well known that EGF receptors increase the intracellular calcium concentration. Therefore, it would be reasonable to conclude that inhibition of MAP kinase kinase and calcium-calmodulin kinase II downregulate aromatase expression in NCI-H295R cells. Interestingly, a PKA inhibitor (H-89) down-regulated aromatase activity. This result suggests that the cAMPPKA pathway is involved in the up-regulation of aromatase 


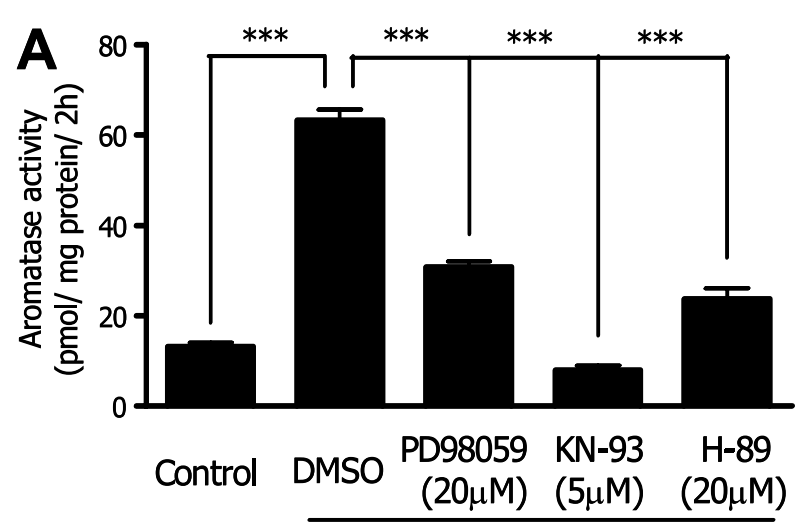

EGF $100 \mathrm{ng} / \mathrm{mL}$

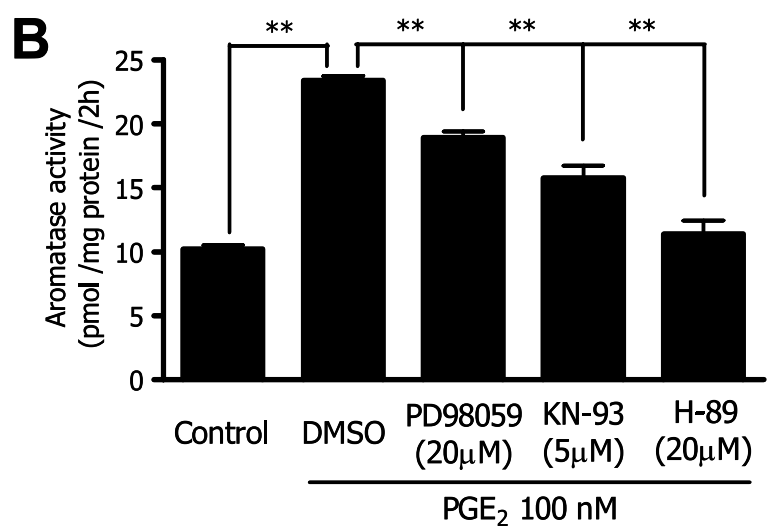

Figure 12 Effect of several protein kinase inhibitors on the increase in aromatase activity in $\mathrm{NCl}-\mathrm{H} 295 \mathrm{R}$ cells with EGF (A) or $\mathrm{PGE}_{2}$ (B). After pretreatment with protein kinase inhibitors for $1 \mathrm{~h}$, cells were treated with protein kinase inhibitors and EGF for $24 \mathrm{~h}$ (A) or protein kinase inhibitors and $\mathrm{PGE}_{2}$ for $4 \mathrm{~h}(\mathrm{~B})$, following which aromatase activity was measured. Each column represents the mean with S.E.M. $(n=3)$. The differences between means were analyzed by one-way ANOVA followed by Tukey's multiple comparison test. Asterisks denote significant differences compared with the vehicle control; ${ }^{*} P<0 \cdot 05 ;{ }^{*} P<0 \cdot 01 ;{ }^{* *} P<0 \cdot 001$. PD98059, inhibitor of MAP kinase kinase; KN-93, inhibitor of calcium-calmodulin kinase; H-89, inhibitor of PKA.

by EGF. Probably a second factor induced by EGF would increase the intracellular cAMP concentration. $\mathrm{PGE}_{2}$ is known to increase the intracellular cAMP concentration. In addition, $\mathrm{PGE}_{2}$ is secreted from NCI-H295R cells in response to EGF (Fig. 13). Furthermore, the induction of aromatase expression with $\mathrm{PGE}_{2}$ might depend mainly on the PKA pathway (Fig. 12B). Thus, $\mathrm{PGE}_{2}$ would be a second factor involved in the up-regulation of aromatase expression by EGF. Up-regulation of aromatase expression with $\mathrm{PGE}_{2}$ appears to depend partially on MAP kinase kinase and calcium-calmodulin kinase II (Fig. 12B). These phenomena could be explained by the existence of $\mathrm{EP}_{1}$, which has some relationship with the signaling pathways involving calcium and the transactivation of EGF receptors with $\mathrm{PGE}_{2}$ (Pai et al. 2002). This signaling pathway would

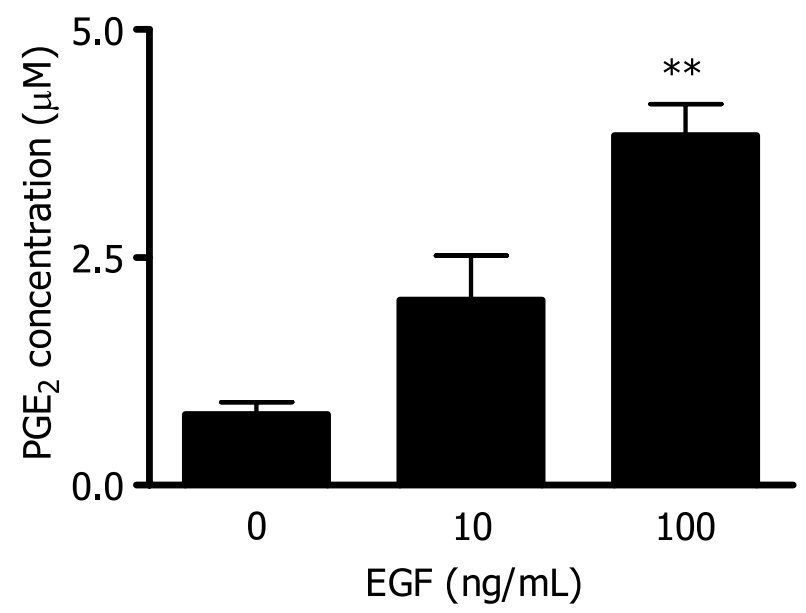

Figure $13 \mathrm{NCl}-\mathrm{H} 295 \mathrm{R}$ cells secrete $\mathrm{PGE}_{2}$ in response to EGF. Cells were treated with EGF for $24 \mathrm{~h}$, then the concentrations of $\mathrm{PGE}_{2}$ in conditioned media were measured. Each column represents the mean with S.E.M. $(n=3)$. The differences between means were analyzed by one-way ANOVA followed by Dunnett's multiple comparison test. Asterisks denote significant differences from the vehicle control $(0 \mathrm{ng} / \mathrm{ml}) ;{ }^{*} P<0 \cdot 01$.

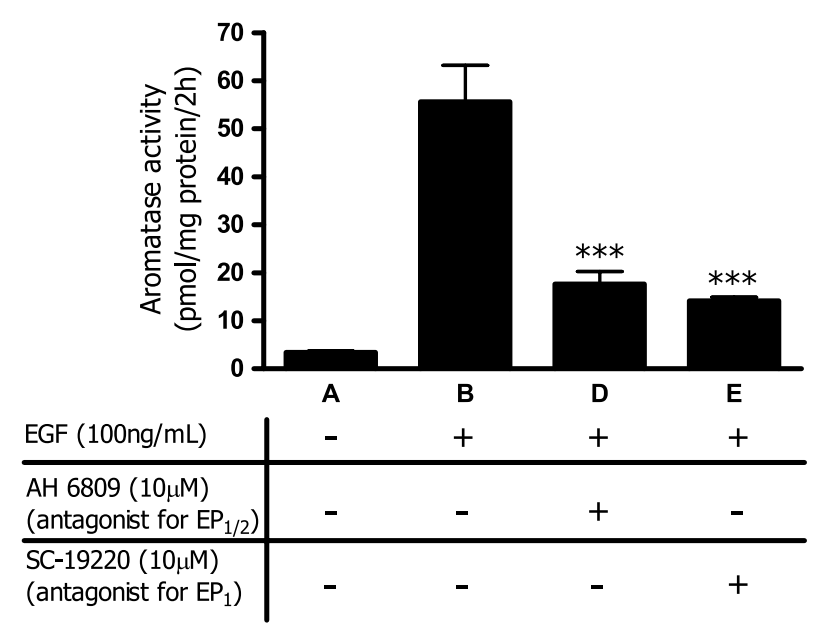

Figure 14 EP receptor antagonists down-regulate aromatase activity in $\mathrm{NCl}-\mathrm{H} 295 \mathrm{R}$ cells induced with EGF. After serum starvation for $24 \mathrm{~h}$, the cells were treated with antagonists and/or EGF for $24 \mathrm{~h}$. Then, aromatase activities were measured. Each column represents the mean with S.E.M. $(n=3)$. The differences were analyzed by one-way ANOVA followed by Dunnett's multiple comparison tests. Asterisks denote significant differences compared with EGF only (column B); ${ }^{* *} P<0 \cdot 001$.

act synergistically with other signals in response to EGF to up-regulate aromatase expression.

The result of the experiments using several agonists and antagonists of $\mathrm{EP}$ receptors suggest that $\mathrm{EP}_{1}$ and $\mathrm{EP}_{2}$ are involved in the up-regulation of aromatase expression but that $\mathrm{EP}_{3}$ is not involved.

In the present study, we showed that EGF and prostaglandins up-regulate aromatase expression in NCI-H295R cells. The autocrine and paracrine system of aromatase 
up-regulation in adrenal tumors is similar to the system in human adipose stromal cells surrounding breast cancer (Richards et al. 2002, Richards \& Brueggemeier 2003). In addition, we investigated the molecular mechanism of the up-regulation of aromatase expression by EGF and $\mathrm{PGE}_{2}$ using promoter analysis and protein kinase inhibitors. However, the up-regulated aromatase activity is lower than the aromatase activity in adrenocortical carcinoma (Watanabe et al. 2000). Therefore, multiple factors, not only EGF and prostaglandins, would synergistically up-regulate aromatase expression at a high level. The search for such factors would help to clarify the mechanism of high level aromatase expression in adrenocortical carcinomas. Finally, it is hoped this search will assist in the development of drugs that down-regulate aromatase expression specifically in adrenocortical carcinomas.

\section{Acknowledgements}

We thank Ono Pharmaceutical Co. Ltd for providing ONO-DI-004 and ONO-AE1-259-01. This work was supported, in part, by a Grant-in-Aid from the Ministry of Education, Culture, Sports, Science and Technology of Japan and by Health Sciences Research Grants from the Ministry of Health, Labour and Welfare of Japan. The authors declare that there is no conflict of interest that would prejudice the impartiality of this scientific work.

\section{References}

Bulun SE, Takayama K, Suzuki T, Sasano H, Yilmaz B \& Sebastian S 2004 Organization of the human aromatase p450 (CYP19) gene. Seminars in Reproductive Medicine 22 5-9.

Doi J, Takemori H, Ohta M, Nonaka Y \& Okamoto M 2001 Differential regulation of 3 beta-hydroxysteroid dehydrogenase type II and 17 alpha-hydroxylase/lyase P450 in human adrenocortical carcinoma cells by epidermal growth factor and basic fibroblast growth factor. Journal of Endocrinology 168 87-94.

Heneweer M, van den Berg M \& Sanderson JT 2004 A comparison of human $\mathrm{H} 295 \mathrm{R}$ and rat $\mathrm{R} 2 \mathrm{C}$ cell lines as in vitro screening tools for effects on aromatase. Toxicology Letters 146 183-194.

Huh YH, Kim SH, Kim SJ \& Chun JS 2003 Differentiation status-dependent regulation of cyclooxygenase-2 expression and prostaglandin $\mathrm{E}_{2}$ production by epidermal growth factor via mitogen-activated protein kinase in articular chondrocytes. Journal of Biological Chemistry 278 9691-9697.

Iwasaki K, Noguchi K, Endo H, Kondo H \& Ishikawa I 2003 Prostaglandin $\mathrm{E}_{2}$ downregulates interleukin-12 production through $\mathrm{EP}_{4}$ receptors in human monocytes stimulated with lipopolysaccharide from Actinobacillus actinomycetemcomitans and interferon-gamma. Oral Microbiology and Immunology 18 150-155.

Moroni M, Veronese S, Schiavo R, Carminati O, Sorensen BS, Gambacorta M \& Siena S 2001 Epidermal growth factor receptor expression and activation in nonseminomatous germ cell tumors. Clinical Cancer Research 7 2770-2775.

Narumiya S \& FitzGerald GA 2001 Genetic and pharmacological analysis of prostanoid receptor function. Journal of Clinical Investigation 108 25-30.
Nishi Y, Yanase T, Mu Y, Oba K, Ichino I, Saito M, Nomura M, Mukasa C, Okabe T, Goto K et al. 2001 Establishment and characterization of a steroidogenic human granulosa-like tumor cell line, KGN, that expresses functional follicle-stimulating hormone receptor. Endocrinology 142 437-445.

Pai R, Soreghan B, Szabo IL, Pavelka M, Baatar D \& Tarnawski AS 2002 Prostaglandin $E_{2}$ transactivates EGF receptor: a novel mechanism for promoting colon cancer growth and gastrointestinal hypertrophy. Nature Medicine 8 289-293.

Phornphutkul C, Okubo T, Wu K, Harel Z, Tracy TF Jr, Pinar H, Chen S, Gruppuso PA \& Goodwin G 2001 Aromatase p450 expression in a feminizing adrenal adenoma presenting as isosexual precocious puberty. Journal of Clinical Endocrinology and Metabolism 86 649-652.

Richards JA \& Brueggemeier RW 2003 Prostaglandin $E_{2}$ regulates aromatase activity and expression in human adipose stromal cells via two distinct receptor subtypes. Journal of Clinical Endocrinology and Metabolism 88 2810-2816.

Richards JA, Petrel TA \& Brueggemeier RW 2002 Signaling pathways regulating aromatase and cyclooxygenases in normal and malignant breast cells. Journal of Steroid Biochemistry and Molecular Biology $80203-212$.

Sasano H, Suzuki T, Shizawa S, Kato K \& Nagura H 1994 Transforming growth factor alpha, epidermal growth factor, and epidermal growth factor receptor expression in normal and diseased human adrenal cortex by immunohistochemistry and in situ hybridization. Modern Pathology 7 741-746.

Sato T, Nakajima H, Fujio K \& Mori Y 1997 Enhancement of prostaglandin $\mathrm{E}_{2}$ production by epidermal growth factor requires the coordinate activation of cytosolic phospholipase A2 and cyclooxygenase 2 in human squamous carcinoma A431 cells. Prostaglandins 53 355-369.

Schlotzer-Schrehardt U, Zenkel M \& Nusing RM 2002 Expression and localization of FP and EP prostanoid receptor subtypes in human ocular tissues. Investigative Ophthalmology and Visual Science 43 1475-1487.

Shozu M, Sebastian S, Takayama K, Hsu WT, Schultz RA, Neely K, Bryant M \& Bulun SE 2003 Estrogen excess associated with novel gain-of-function mutations affecting the aromatase gene. New England Journal of Medicine 348 1855-1865.

Suzawa T, Miyaura C, Inada M, Maruyama T, Sugimoto Y, Ushikubi F, Ichikawa A, Narumiya S \& Suda T 2000 The role of prostaglandin $\mathrm{E}$ receptor subtypes $\left(\mathrm{EP}_{1}, \mathrm{EP}_{2}, \mathrm{EP}_{3}\right.$, and $\left.\mathrm{EP}_{4}\right)$ in bone resorption: an analysis using specific agonists for the respective EPs. Endocrinology 141 1554-1559.

Watanabe M \& Nakajin S 2004 Forskolin up-regulates aromatase (CYP19) activity and gene transcripts in the human adrenocortical carcinoma cell line H295R. Journal of Endocrinology 180 125-133.

Watanabe T, Yasuda T, Noda H, Wada K, Kazukawa I, Someya T, Minamitani K, Minagawa M, Wataki K, Matsunaga T et al. 2000 Estrogen secreting adrenal adenocarcinoma in an 18-month-old boy: aromatase activity, protein expression, mRNA and utilization of gonadal type promoter. Endocrine Journal 47 723-730.

Young J, Bulun SE, Agarwal V, Couzinet B, Mendelson CR, Simpson ER \& Schaison G 1996 Aromatase expression in a feminizing adrenocortical tumor. Journal of Clinical Endocrinology and Metabolism 81 3173-3176.

Zhao Y, Agarwal VR, Mendelson CR \& Simpson ER 1996 Estrogen biosynthesis proximal to a breast tumor is stimulated by $\mathrm{PGE}_{2}$ via cyclic AMP, leading to activation of promoter II of the CYP19 (aromatase) gene. Endocrinology 137 5739-5742.

Received in final form 23 September 2005

Accepted 13 October 2005

Made available online as an Accepted Preprint

9 November 2005 